\title{
Spatio-temporal patterns in the abundance and population structure of a large temperate reef fish
}

\author{
Mark I. McCormick \\ University of Auckland, Leigh Marine Laboratory, R.D. Leigh, New Zealand
}

\begin{abstract}
Density, size structure and sex distribution of the large temperate reef fish Cheilodactylus spectabilis were examined in 10 habitats on a rocky reef environment in northeastern New Zealand. Morphometric analysis of body form identified subtle features which enabled the sex of $C$. spectabilis to be identified readily in the field. Censuses of mapped areas and strip-transect counts were used to monitor the distribution patterns down a depth gradient at 2 localities over a 12 mo period (1985). Large differences in density, size and sex structure were found between habitats. Females and juveniles were found to inhabit the shallow sections of the reef, while males dominated the deeper regions. There was a strong trend toward increased mean fish size with depth. These trends in distribution, density and size were consistent over a wide range of time scales. Comparisons with surveys conducted in 1978 and 1988 showed the same patterns of distribution and population structure. Similar consistency was found on a between-month, between-day and within-day scale over a range of depths.
\end{abstract}

\section{INTRODUCTION}

Cheilodactylus spectabilis (Hutton) is a large temperate fish which is common on the shallow coastal reefs of northern New Zealand and southern Australia. It is one of a group of demersal microcarnivores which have been implicated as highly influential in governing the distribution of invertebrates associated with turfing algae and encrusting communities (Leum \& Choat 1980, Russ 1980, Ayling 1981). Others in this group include sparids, monocanthids and labrids. Unfortunately attempts to determine the effect of these fishes on the distribution of their benthic prey have been hampered by a lack of detailed information on the fishes' abundance patterns (Choat 1982). The root of this problem is the patchy distribution of these fish in both space and time, a common feature of reef fish populations. This is intimately tied to the patchiness of the environment with which they associate for shelter and food (e.g. Holbrook \& Schmitt 1984, Jones 1984a, Choat \& Ayling 1987).

Much of the local variation in distribution patterns can probably be attributed to systematic trends involving particular size and sex stages of the fish population (e.g. Helfman 1978, Jones 1984c). Many reef fish

- Present address: Department of Marine Biology, James Cook University, Queensland 4811, Australia undergo regular size-related feeding migrations IOgden \& Buckman 1973, Gladfelter 1979, Helfman et al. 1982). Furthermore, the outcome of behavioural interactions, prey selection, and entrance into the reproductive population are often size dependent (Werner \& Gilliam 1984, Jones 1984a, c, 1987). Unfortunately, so few studies have examined the factors influencing a species distribution in detail, that the influence of size and sex on population dynamics is largely unknown (exceptions Jones 1984a,b,c, Hoffman 1985).

This study describes the patterns of size and sex distribution of Cheilodactylus spectabilis on the rocky reefs of northeastern New Zealand, over a range of spatial and temporal scales. Moreover, it examines how size and sex might influence our perception of how the fish is distributed, and its effect on the local environment. Data spanning a 10 yr period between 1978 and 1988 is presented for a range of reef habitats, and density and size trends are examined. Such long-term information is important if conclusions are to be made regarding the processes affecting the distribution of the population and the potential effects of the population on its environment (Jones 1988). Single surveys may lead to a unrepresentative picture of spatial patterns and species/size/sex related associations. Spatial patterns of density and size structure are also examined on the finer within- and between-day, and within-year scales. 
Since morphologically the sexes of the gonochoristic Cheilodactylus spectabilis are very similar, the first element of this study was the identification of characteristics which would allow rapid sexing of individuals in the field.

\section{MATERIALS AND METHODS}

Study sites. The study was conducted in the $5 \mathrm{~km}$ of shallow rocky reef which makes up the Cape Rodney to Okakari Point Marine Reserve, on the northeastern coast of New Zealand. The reef contains a variety of recognizable habitat types, which often have discrete boundaries (see McCormick \& Choat 1987, Table 1, for description).

Morphology. A morphological analysis was carried out to determine whether Cheilodactylus spectabilis was sexually dimorphic. Body measurements were taken on a sample of 32 fish (17 males, 15 females), ranging in size from 132 to $451 \mathrm{~mm}$ SL (standard length). Nineteen measurements of body form were recorded (given in Fig. 1, plus a measure of anal fin length, lip size and wet weight). An additional 2 descriptors of form were calculated: (a) snout angle the difference between the dorsal head angle and snout acuteness; (b) anus position - the proportion that the anterior anal length is of the posterior anal length.

Patterns of spatial abundance with size and sex. A optimum stratified-random survey to determine the total abundance of Cheilodactylus spectabilis in the $5 \mathrm{~km}$ Reserve was documented by McCormick \& Choat (1987). Information collected on the size and sex structure of the C. spectabilis population within a variety of temperate reef habitats is presented here. During this survey, the standard length of each fish seen within $20 \times 5 \mathrm{~m}$ strip transects was estimated. Estimates of size prior to destructive sampling or measurement in the field were found to be accurate to within $10 \%$. Each fish was placed into one of 3 categories: male, female and unknown. The unknown category was composed mainly of juveniles (below $250 \mathrm{~mm}$ SL). Destructive sampling of fish outside the study area following estimation of sex yielded $100 \%$ accuracy for fish greater than $240 \mathrm{~mm}$ SL. However, this is based on a sample of only 5 fish. Inaccurate sexing in the field is a potentially confounding factor in the description of the patterns of the sex distribution in C. spectabilis. However, inaccuracies are thought to be few, being mostly of the smaller fish around $250 \mathrm{~mm}$ SL.

Temporal change in abundance and size frequency. To examine the fluctuations in density and size structure of the Cheilodactylus spectabilis population over time, 2 strips of reef were surveyed daily and/or monthly over the period from January to December
1985. The ca $100 \times 350 \mathrm{~m}$ localities encompassed in this study were Tabletop and Onespot reefs which are separated by $0.75 \mathrm{~km}$ of coast. These strips consisted of 2 habitat types: 'shallow broken rock' in the shallows, and 'dissected blocks' in deeper water. Both sloped to a depth of $25 \mathrm{~m}$ some $350 \mathrm{~m}$ offshore. Both reefs were divided arbitrarily into 3 depth zones: shallow $(<9 \mathrm{~m})$, mid $(9-17 \mathrm{~m})$ and deep (17-23 m). Part way through the monitoring programme a fourth, deeper site was added to the Tabletop reef locality, this was separated from the main reef by a large sand flat; subsequently, deep zones became Deep $1(17-23 \mathrm{~m})$ and Deep $2(>23 \mathrm{~m})$. This Deep 2 site was composed of 'deep-flat-reef' habitat. No such site was available for the Onespot location.

Two methods were used to assess changes in the density and population structure of Cheilodactylus spectabilis at the 2 locations: (a) total censuses (Tabletop) and (b) strip-transects (Onespot). Total censuses were used at the Tabletop locality to enable a detailed examination of the local spatial distribution patterns and social organization of $C$. spectabilis, not presented in this paper. Since this is a time-consuming survey method, the more rapid visual strip transect technique was used at the Onespot locality.

The Tabletop reef total census required a $100 \times$ $350 \mathrm{~m}$ strip of reef to be mapped in detail. Each of the 3 depths was censused separately and the size of all Cheilodactylus spectabilis seen was estimated (SL), each individual was sexed, and the position of each fish was plotted on a map of the area. Recount of fish were minimized through the recognition of individuals seen previously during the census, by scars and irregularities in banding patterns of the fish.

Random strip transects were used to quantify density patterns at Onespot reef. McCormick \& Choat (1987) found that a $20 \times 5 \mathrm{~m}$ strip transect was the most efficient size when sampling Cheilodactylus spectabilis. The time constraints of diving allowed a maximum of 8 transects to be swum at the deepest study site at Onespot. Power analysis indicated that 8 replicates were adequate to detect small to moderate differences in density (as defined by Cohen 1977) between depths (effect size $=0.19, n=80$ ) and moderate differences in density over time (effect size $=0.35$, $n=24)$. Thus 8 transects of $20 \times 5 \mathrm{~m}$ were used to assess the density of $C$. spectabilis at each of the 3 depths for the 12 mo monitoring period. All fish seen during transect sampling were used in an analysis of size frequency patterns. The trends in sex distribution over time were not assessed due to inconsistent recognition of sex in the early months of study.

Within and between days: Variations in the density, size structure and spatial distribution of Cheilodactylus spectabilis with time of day were investigated at 
Tabletop reef. Replicated censuses were swum at 3 times of the day (dawn, dusk and midday) over the shallow and mid-depth sites. The mid-Tabletop reef study site was censused 3 times of the day for $2 \mathrm{~d}$ during November 1984. This census series was repeated over $3 \mathrm{~d}$ during November 1985 to determine whether the within- and between-day patterns obtained were consistent over years. At the shallow site the within-day changes in size distribution were assessed in 2 parts due to adverse weather conditions. Both involved 2 replicate censuses at 2 times of the day (dawn and midday; dawn and dusk). A small-scale within-day movement pattern at the Deep 2 Tabletop study site around the reproductive season (April) suggests a small potential sampling bias with regard to the time of day. This movement pattern is the subject of another paper (McCormick 1989).

Between months: All 3 depth sites at Tabletop and Onespot Reefs were surveyed once per month for $12 \mathrm{mo}$, to examine whether there were systematic trends in movement patterns within a year. Strip transects were used at Onespot, while total count censuses were employed at Tabletop Reef. These censuses were assumed to be representative of the density, size and sex distributions for a specific month.

Between years: The density and size distributions of Cheilodactylus spectabilis in the 5 habitats where it was most common were sampled during February 1988. Three sites were sampled for each of the shallow broken rock, kelp, deep reef, and rock flat habitats, with 10 transects within each. Only one site was available for the tumble boulderbank habitat. Size structure and density estimates from this survey are compared to the more extensive 1985 survey, and also with the results of a similar survey conducted in 1978 (Ayling unpubl.)

Analyses. Multivariate pattern-analysis techniques were used to identify potential differences in body shape between male and female fish. The set of 21 measured body variables was reduced to a more manageable number by the removal of highly collinear variables and those which discriminated least between male and female fishes. This was accomplished by stepwise canonical discriminant analysis. To test whether male and female fish did differ in form, a multivariate analysis of variance was performed on the reduced variable set. Data was examined for multivariate normality and homeogeneity of variance. A canonical discriminant analysis identified the nature and extent of any significant differences found.

To enable statistical comparisons of Cheilodactylus spectabilis densities between the Tabletop and Onespot localities over time, census data from the Tabletop study site was converted to transect data by the stimulation of transects over the mapped populations (see
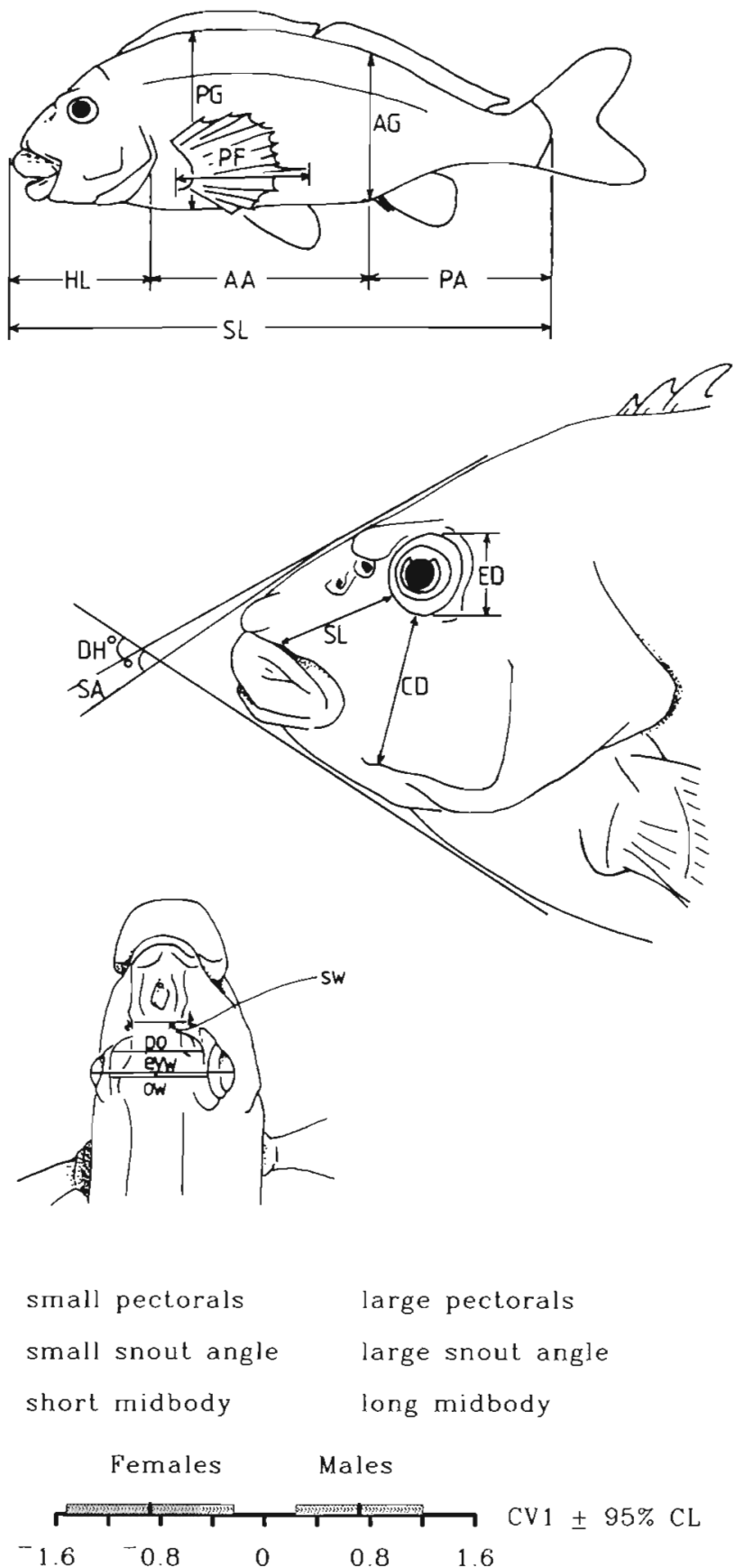

Fig. 1. Cheilodactylus spectabilis. Lateral body, lateral head, and dorsal head views, showing positions of morphological reference lines. Results of a canonical discriminant analysis identifying which body features differ between males and females are listed below. Position of male and female body characteristics along the first canonical variate is shown, with $95 \%$ confidence limits. Abbreviations: SL, standard length; $A G$, anal girth; $P G$, pectoral girth; PA, posterior anal length; $A A$, anterior anal length; $P F$, pectoral fin length; $H L$, head length; SA, snout acuteness; $\mathrm{DH}$, dorsal head angle; CD, cheek depth; SL, snout length; ED, eye diameter; SW, snout width; PO, preorbital width; EYW, eye diameter; OW, interorbital width 
McCormick \& Choat 1987). No data was collected to determine whether simulated transect sampling yields results indistinguishable from real field sampling. Consequently, analyses are interpreted cautiously.

Analysis of variance was used to test the effect of the factors, time of day, days and months on the abundance patterns of Cheilodactylus spectabilis. Residual analysis was used to check the ANOVA assumptions of normality and homogeneity of variances. If data deviated from these assumptions the data was transformed $(\log [x+1])$ and residuals re-examined. To enable analysis of the changes in size frequency distributions, fishes were placed into one of 4 size classes. These were: $\mathrm{A}: \mathrm{SL} \leq 250 \mathrm{~mm} ; \mathrm{B}: 250<\mathrm{SL} \leq 350 \mathrm{~mm} ; \mathrm{C}: 350$ $<\mathrm{SL} \leq 450 \mathrm{~mm} ; \mathrm{D}: \mathrm{SL}>450 \mathrm{~mm}$. These do not represent wholly arbitrary divisions of the population. Information on the reproductive cycle suggests $C$. spectabilis mature at $250 \mathrm{~mm}$ SL (McCormick 1989), thus the smallest size class represents juveniles. Furthermore, information presented in this study suggests that the largest size class contains mostly males. Variations in the size composition were analyzed by multidimensional contingency table analysis using maximum likelihood estimation (CATMOD, SAS 1985). These have the benefits of being able to examine interacting factors on discrete datasets (Legendre 1987).

\section{RESULTS}

\section{Morphology}

A multivariate analysis of variance indicated a significant difference in body shape amongst male and female Cheilodactylus spectabilis (Pillai's trace 0.35, d.f. $=5,26, p<0.036)$. A canonical discriminant analy-

Table 1 Cheilodactylus spectabilis. Summary of abundance within 10 habitats, plus percentage that each habitat comprises of the $5 \mathrm{~km}$ section of coast surveyed (from McCormick \& Choat 1987). Depth ranges are given for each habitat. $n$. number of strip transects used in each habitat

\begin{tabular}{|c|c|c|c|c|c|}
\hline Habitat & $n$ & ${ }_{\bar{x}}^{\text {No. per }}$ & $\begin{array}{c}100 \mathrm{~m}^{2} \\
\mathrm{SD}\end{array}$ & $\%$ Area & $\begin{array}{c}\text { Depth } \\
\text { (m) }\end{array}$ \\
\hline Shallow broken rock & 32 & 2.09 & 2.01 & 20 & $1-8$ \\
\hline Rock flat & 85 & 0.61 & 1.10 & 35 & $4-12$ \\
\hline Kelp forest & 44 & 0.93 & 1.04 & 23 & $7-22$ \\
\hline Dissected blocks & 8 & 1.50 & 1.77 & 4 & $5-20$ \\
\hline Tumble boulderbank & 41 & 15.87 & 14.94 & 1 & $12-22$ \\
\hline Deep reef & 7 & 1.71 & 1.50 & 4 & $18-24$ \\
\hline Deep flat reef & 6 & 2.00 & 1.26 & 2 & $22-25$ \\
\hline Sponge garden & 4 & 0.25 & 0.50 & 5 & $16-20$ \\
\hline Mixed rock and sand & 11 & 0.36 & 0.67 & 3 & $1-15$ \\
\hline Sediment flats & 3 & 0 & 0 & 4 & $5-16$ \\
\hline
\end{tabular}

sis identified the body measurements which were most important in differentiating between the sexes (Fig. 1). Males were found to differ from females in 3 main ways: males had a relatively larger snout angle, a longer mid-body, and longer pectoral fins than females. The high snout angle in males is due to crest-like protuberances on the preorbital bone of the skull. Field observations indicate that these protuberances

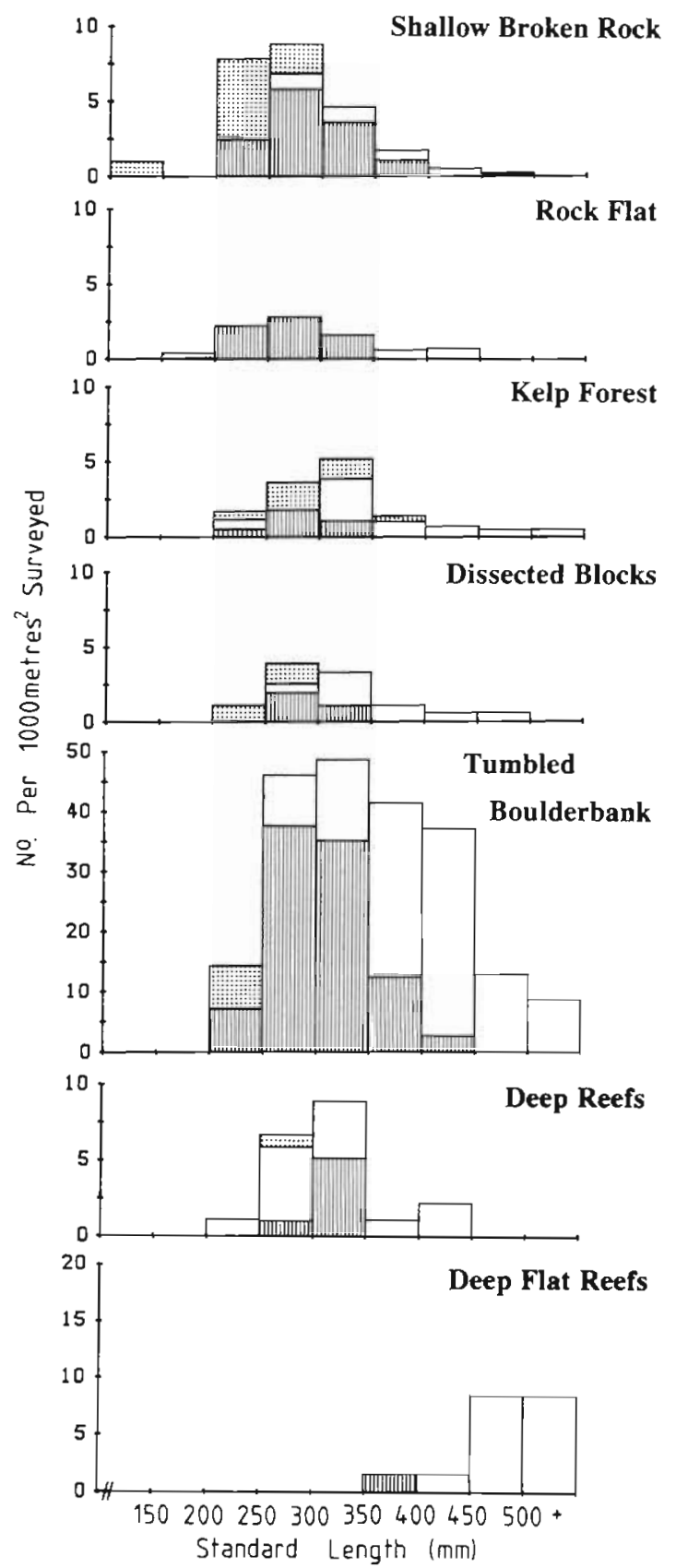

Fig. 2. Cheilodactylus spectabilis. Size-frequency histograms by habitat showing sexual composition. Data from a stratified survey of $5 \mathrm{~km}$ of coast. Histograms ordered by depth. Open bars: males; striped bars: females; stippled bars: juveniles 
develop fleshy nodules or papillae in breeding males. These nodules, in combination with snout angle, midbody length and pectoral fin size allow the rapid sexing of individuals in the field down to $240 \mathrm{~mm}$ SL.

\section{Spatial patterns of abundance}

McCormick \& Choat (1987) described patterns of abundance of Cheilodactylus spectabilis in 10 habitat types. To aid interpretation of the size-and sex-related patterns of abundance these are summarized in Table 1. The size range has been divided into $50 \mathrm{~mm}$ size classes to examine general trends in size and sex distribution with habitat type. There was a general trend for the smallest fish $(<150 \mathrm{~mm} \mathrm{SL})$ to occur in the shallower habitats, while larger fish occur in progressively deeper water. A regression of size (SL) on depth for all fishes where depth was recorded was significant $\left(r^{2}=0.43, n=178, p<0.001\right)$.

The size/sex distribution suggests that males attain a larger maximum size than females, with the largest male observed estimated at $530 \mathrm{~mm}$ SL compared to $440 \mathrm{~mm}$ SL for females (Fig. 2). Furthermore, the sex distribution showed a trend for large males to dominate the deeper habitats, while females and juveniles are most abundant in the shallows. These size and sex related trends are clear from a comparison between the rock flat ( 4 to $12 \mathrm{~m}$ depth) and deep flat reef habitats (22 to $25 \mathrm{~m}$ ). Females make up $80 \%$ of the Cheilodactylus spectabilis population in the former, while representing only $8 \%$ in the latter habitat. In addition, no males larger than $450 \mathrm{~mm}$ SL were present on the rock flats, while none smaller than $400 \mathrm{~mm}$.
SL occurred in the deep flat reefs. Within the tumbled boulderbank habitat most females were found between 12 and $16 \mathrm{~m}$ depth, while males were common down to $22 \mathrm{~m}$.

Similar size- and sex-related patterns with depth were shown at the regularly monitored Tabletop and Onespot locations (Fig. 3). These trends are not as distinct at the Onespot study site, with fewer males greater than $450 \mathrm{~mm}$ standard length at the deep site. This may be due to the lack of a 'deep-flat-reef' habitat at the offshore edge of the reef (Tabletop Deep 2).

\section{Temporal abundance patterns}

Density and size-structure of Cheilodactylus spectabilis at mid-depth Tabletop reef showed little change within or between days (Fig. 4). A 3-factor analysis of variance comparing densities over 3 times of the day, 2 days and between 2 censuses 1 yr apart, revealed no significant changes in density (Table 2). Similarly small portions of the total variation in C. spectabilis density were explained by differences in density between years, days and times of day $(0.6,1.5,0.8 \%$ respectively). The majority of the variation in density was due to the difference among strip transects (95\%). In addition, a maximum likelihood analysis found no significant differences between size frequency distributions over the 2 census series, time of day or days (Table 3 ).

Two census programmes at the shallow Tabletop site found a similarly small change in abundance and size structure with time of day. The series of 4 censuses ( 2 times of day over 2 d) during May revealed no significant difference in density (Fig. 5) or size frequency
Fig. 3. Cheilodactylus spectabilis. Size-frequency distributions indicating sex composition, at 4 depths at the Tabletop study site and 3 depths at Onespot. Standard errors are for total densities in each size class, and were calculated from 11 monthly censuses of each depth/locality combination. Sexes are identified as in Fig. 2. Size classes: A: $\mathrm{SL} \leq 250 \mathrm{~mm}$; B: $250<\mathrm{SL} \leq 350 \mathrm{~mm}$. C: $350<\mathrm{SL} \leq 450 \mathrm{~mm} ; \mathrm{D}: \mathrm{SL}>450 \mathrm{~mm}$

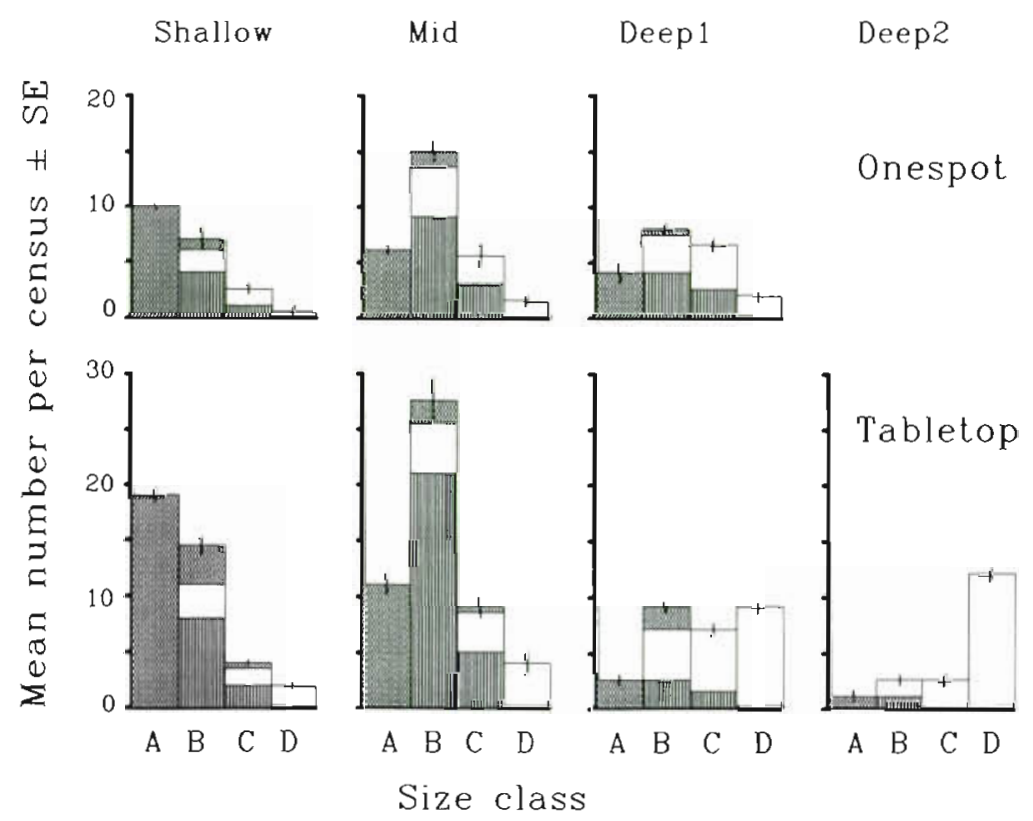


Table 2. Cheilodactylus spectabilis. Analysis of variance comparing densities at the mid-depth Tabletop study site over 3 times of the day, $2 \mathrm{~d}$ and 2 census series 1 yr apart. Percentage of total variation explained by each term is given (\%); formula from Winer (1971). Log $(x+1)$ transformed. ns: non-significant at the 0.05 level, $n=20$ simulated transects

\begin{tabular}{|lrrrrr|}
\hline Source & d.f. & MS & $F$-value & Significance \\
\hline Years & 1 & 0.254 & 15.89 & ns & \\
Times & 2 & 0.256 & 7.61 & ns & 0.6 \\
Days (Years) & 2 & 0.016 & 0.05 & ns & \\
Years $\times$ Times & 2 & 0.034 & 0.13 & ns & 1.5 \\
Times $\times$ Days (Years) & 4 & 0.270 & 0.79 & & ns \\
Residual & 228 & 0.343 & & & 94.5 \\
\end{tabular}

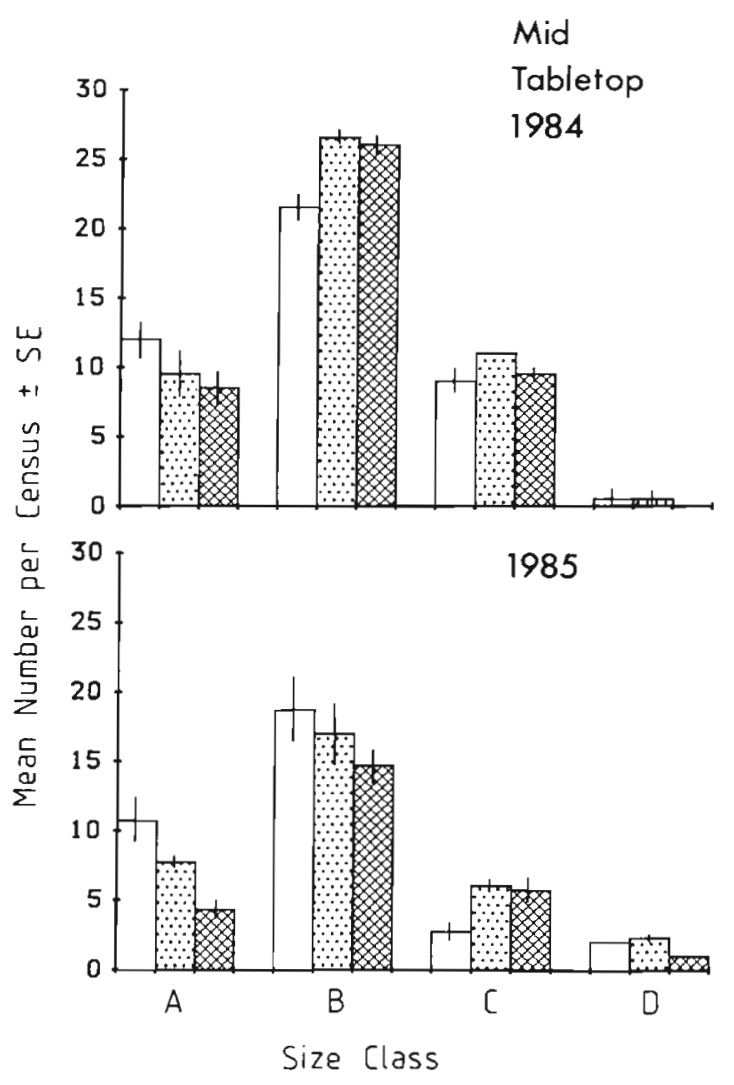

Fig. 4. Cheilodactylus spectabilis. Within and between-day variation in size structure at the mid Tabletop study site. Numbers per census with standard errors over 3 times of day are given for November 1984 and November 1985. Amount of between-day variation is indicated by error bars. Open bars: dawn; stippled bars: midday: cross-hatched bars: dusk. Size classes as in Fig. 3

(Table 4a) between dawn and dusk censuses, over 2 consecutive days. The intercept values were significant in both instances. Likewise, a similar set of 4 censuses during June, comparing densities between midday and dusk over $2 \mathrm{~d}$, found no significant differences (Fig. 5 , Table $4 \mathrm{~b}$ ). This suggests that the density and sizestructure of Cheilodactylus spectabilis changes little over a number of days, at least at shallow and mid-
Table 3. Cheilodactylus spectabilis. Maximum likelihood analysis comparing size frequency distributions at the midTabletop site over 2 census series 1 yr apart, 2 random days and 3 times of day (dawn, midday, dusk). Degrees of freedom and chi-square statistic used in the analysis are given. ns: nonsignificant at the 0.05 level

\begin{tabular}{|lccc|}
\hline Source & d.f. & Chi-square & Significance \\
\hline Year & 3 & 3.92 & $\mathrm{~ns}$ \\
Day & 3 & 2.06 & $\mathrm{~ns}$ \\
Time & 6 & 5.50 & $\mathrm{~ns}$ \\
Year $\times$ Day & 3 & 3.99 & $\mathrm{~ns}$ \\
Year $\times$ Time & 6 & 4.46 & $\mathrm{~ns}$ \\
Day $\times$ Time & 6 & 3.99 & $\mathrm{~ns}$ \\
Year $\times$ Day $\times$ Time & 6 & 4.11 & $\mathrm{~ns}$ \\
\hline
\end{tabular}

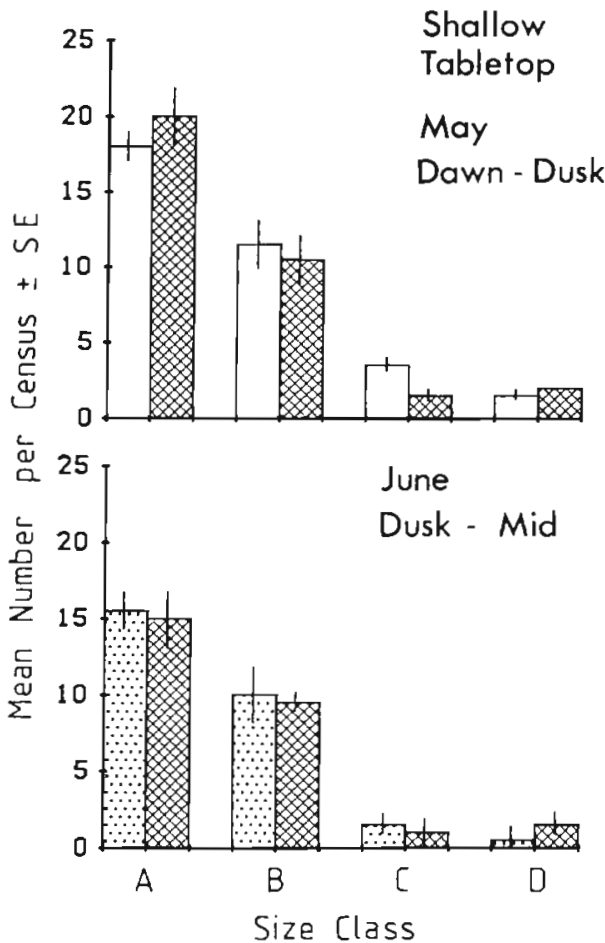

Fig. 5. Cheilodactylus spectabilis. Within- and between-day variation in size structure at the shallow Tabletop study site. Two census series are presented, the first comparing dawn and dusk, the second, dusk and midday. Size classes as in Fig. 3 
Table 4. Cheilodactylus spectabilis. Comparison of size frequency distributions at shallow Tabletop site over 3 times of day: a 2-step comparison. Categorical analyses of size structure using Maximum Likelihood estimation are used to compare between: (a) dawn and dusk samples (b) midday and dusk samples

\begin{tabular}{|lccc|}
\hline Source & d.f & Chi-square & Significance \\
\hline (a) Dawn - Dusk & & & \\
Days & 3 & 1.02 & ns \\
Time & 3 & 2.00 & ns \\
Time $\times$ Days & 3 & 0.11 & ns \\
(b) Midday - Dusk & & & \\
Days & 3 & 1.70 & ns \\
Time & 3 & 0.56 & ns \\
Time $\times$ Days & 3 & 0.26 & ns \\
\hline
\end{tabular}

depths. Moreover, it suggests that a single census may yield an estimate of population structure that is representative of the true population within the sampled area for a number of days.

Monthly monitoring of Tabletop and Onespot locations over a 12 mo period revealed no significant changes in Cheilodactylus spectabilis density for any of 3 depths analysed (Table 5). Similarly, there was no change in the size structure of either population over this period (Table 6). This is despite the fact that the total numbers of $C$. spectabilis for all size classes over the whole of the Tabletop study site fluctuated by between $55 \%(\mathrm{SL} \leq 450 \mathrm{~mm})$ and $71 \%(350 \leq \mathrm{SL}<$ $450 \mathrm{~mm}$ ) of their maximum value (Fig. 6). Only 2 changes in the rank abundance of the 4 size classes occurred (May and August), and these were between the 2 least abundant size classes ( $C$ and $D$, see Fig. 6 ).

Since Tabletop reef is only part of the larger reef network, some emigration and migration is likely to have occurred. The trend in fluctuations of the total number of Cheilodactylus spectabilis counted at Tabletop over the $12 \mathrm{mo}$ period mirrors those of the most abundant, 250 to $350 \mathrm{~mm} \mathrm{SL}$, size class (Fig. 6). Behavioural studies suggest that fish within this size
Table 6. Cheilodactylus spectabilis. Maximum Likelihood analysis comparing size frequency distributions over $11 \mathrm{mo}, 3$ depths and 2 locations. '. Significant at the 0.0001 level

\begin{tabular}{|lrrc|}
\hline Source & d.f. & Chi-square & Significance \\
\hline Locality & 3 & $<0.001$ & $\mathrm{~ns}$ \\
Month & 30 & 42.09 & $\mathrm{~ns}$ \\
Depth & 6 & 91.75 & $\cdots$ \\
Locality $\times$ Month & 30 & 18.20 & $\mathrm{~ns}$ \\
Locality $\times$ Depth & 6 & 1.10 & $\mathrm{~ns}$ \\
Month $\times$ Depth & 60 & 52.86 & $\mathrm{~ns}$ \\
Locality $\times$ Month $\times$ Depth & 60 & 34.80 & $\mathrm{~ns}$ \\
\hline
\end{tabular}

range have the largest home-ranges (Leum \& Choat 1980, McCormick 1986, 1989). The decline in numbers from April to July 1985 may be due to an extension of the home-range size during winter, and consequently, a lower chance of recording an individual in the census area. This decline in numbers was consistent over all depths and was insufficiently large to be statistically

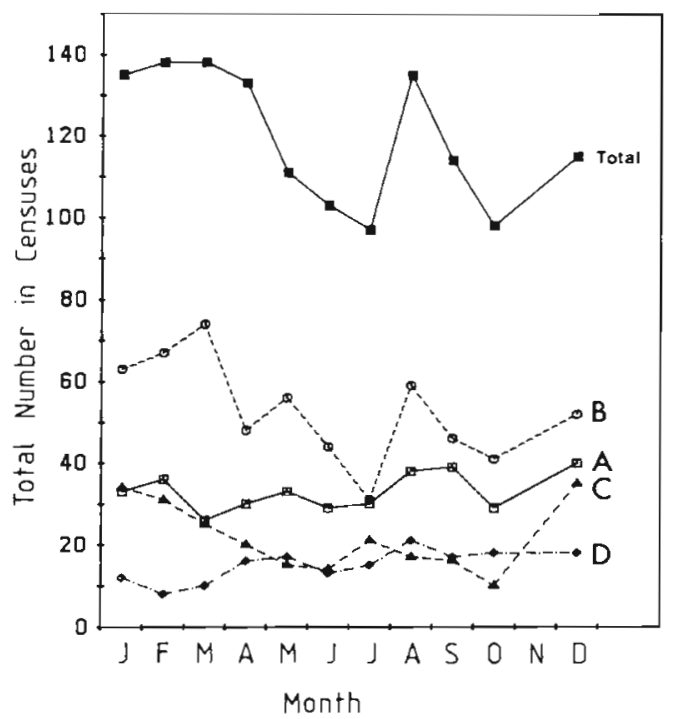

Fig. 6. Cheilodactylus spectabilis. Total number censused over the Tabletop study site over 12 mo. Letters A to D represent size classes as given in Fig. 3

Table 5. Cheilodactylus spectabilis. Analysis of variance comparing densities at Tabletop and Onespot study sites over 3 depths and $11 \mathrm{mo} . \log (x+1)$ transformed; $n=8$. $\cdots$ Significant at 0.001 level

\begin{tabular}{|c|c|c|c|c|}
\hline Source & d.f. & MS & $F$-value & Significance \\
\hline Location & 1 & 0.868 & 2.52 & ns \\
\hline Month & 10 & 0.454 & 1.31 & ns \\
\hline Depth & 2 & 1.515 & 4.40 & $\cdots$ \\
\hline Loc. $\times$ Month & 10 & 0.138 & 0.40 & ns \\
\hline Loc. $\times$ Depth & 2 & 0.448 & 1.30 & ns \\
\hline Month $\times$ Depth & 20 & 0.318 & 0.92 & ns \\
\hline Loc. $\times$ Month $\times$ Depth & 20 & 0.310 & 0.90 & ns \\
\hline Residual & 462 & 0.344 & & \\
\hline
\end{tabular}


detected over normal spatial variation with the present sampling design.

The overriding trend, both in terms of the density and size structure of Cheilodactylus spectabilis, was with depth. Significant differences in density and size occurred, and these were consistent over time (Tables 5 and 6). A Tukey's HSD test revealed that the densities of C. spectabilis at mid-depth sites were significantly higher than those from either deep or shallow sites.

When the density of Cheilodactylus spectabilis was compared between surveys spanning a 10 yr period the differences in density between habitats noted within a year were found to be relatively consistent over a number of years. Over the 3 surveys the rank order of the fish densities by habitat remained unchanged (Table 7). The highest densities of C. spectabilis were always found in the tumble boulderbank habitat, while the lowest densities were recorded on the rock flat areas.

Similarly, the size structure of Cheilodactylus spectabilis within the 4 main habitats shows little change over the 10 yr period (Fig. 7). The smallest individuals were consistently found in the shallow broken rock areas. This was accentuated by the successful settlement during summer 1977-78. Extensive diving in the survey area between 1978 and 1988 suggests that this was the only large recruitment of $C$. spectabilis into the area during the period. The 300 to $350 \mathrm{~mm}$ SL size class still remained the mode in the kelp forest and deep reef habitats.

\section{DISCUSSION}

The wide variation in the density of Cheilodactylus spectabilis between habitats within the $5 \mathrm{~km}$ survey area is consistent with all studies that have investigated fish distributions at that scale, in both temperate and tropical systems (Ebeling et al. 1980, Kingett \& Choat 1981, Jones 1984b, Russ 1984a, b, Choat \& Bellwood 1985, Choat \& Ayling 1987). Less predictable were the differences in size and sex distribution between habitats. A bell-shaped size structure was the norm, with its modal size class differing between habitats. The position of the most abundant size class was loosely related to habitat depth, with larger individuals occurring at higher densities in deeper water. Excep-

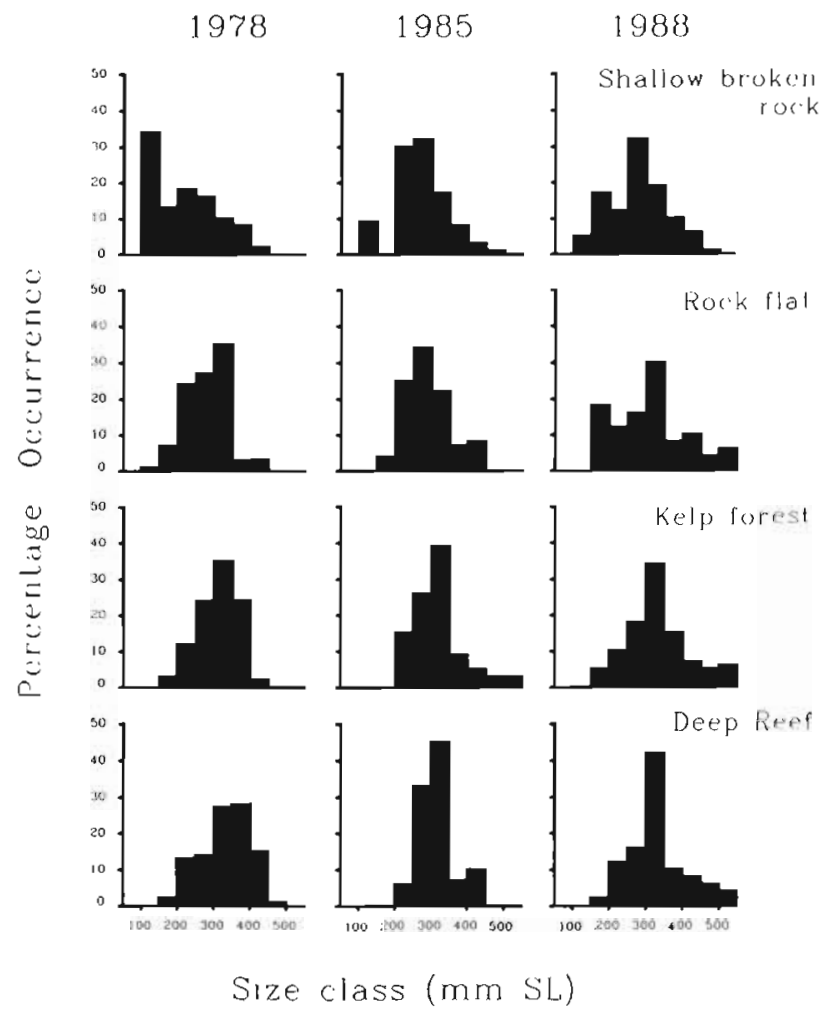

Fig. 7. Cheilodactlyus spectabilis. Comparison of size structure in 4 habitats at the Cape Rodney to Okakari Point Marine Reserve between 1978, 1985 and 1988 surveys

Table 7 Cheilodactylus spectabilis. Comparison of densities in 7 habitats at Goat Island Bay between 1978 and 1988 . Mean number per $100 \mathrm{~m}^{2}$ plus standard deviations are given, together with replicate number (n). 1978 counts from Ayling (unpubl.) with 1 exception. Estimates for 'Tumble boulderbank' habitat in 1978 from Leum \& Choat (1980; Area 8). This estimate is for the same general site but not necessarily within same habitat boundaries as the 1985 and 1988 surveys

\begin{tabular}{|c|c|c|c|c|c|c|}
\hline \multirow[t]{2}{*}{ Habitat } & \multicolumn{6}{|c|}{ No. C. spectabilis per $100 \mathrm{~m}^{2}$} \\
\hline & $n$ & 1978 & $n$ & 1985 & $n$ & 1988 \\
\hline Shallow broken rock & 25 & $1.66 \pm 2.23$ & 32 & $2.09 \pm 2.01$ & 30 & $1.50 \pm 1.46$ \\
\hline Rock flat & 50 & $0.28 \pm 1.02$ & 85 & $0.61 \pm 1.10$ & 30 & $0.80 \pm 1.13$ \\
\hline Kelp forest & 25 & $0.77 \pm 1.30$ & 44 & $0.93 \pm 1.04$ & 30 & $1.03 \pm 1.25$ \\
\hline Tumble boulderbank & 15 & $4.24 \pm 1.45$ & 41 & $15.87 \pm 14.94$ & 10 & $14.0 \pm 19.15$ \\
\hline Deep reef & 15 & $1.27 \pm 1.38$ & 7 & $1.71 \pm 1.50$ & 30 & $1.27 \pm 1.39$ \\
\hline Sediment flat & 10 & $0.08 \pm 0.18$ & 3 & 0 & & nd \\
\hline Sponge gardens & 10 & 0 & 4 & $0.25 \pm 0.5$ & & nd \\
\hline
\end{tabular}


tions to this normal distribution were the skewed size distributions of shallow-broken-rock and deep-flat-reef habitats. Juveniles only settled into the surge channels of the former, which had a predominance of smaller individuals. In contrast, the latter was characterized by a lack of small and an abundance of very large fish.

The sex distribution was closely associated with this size pattern. Females and juveniles dominated the shallow habitats while males, which grow to a larger size, were most abundant in the deepest parts of the reef. Patterns of size structure over strips of reef running offshore suggest a slow ontogenetic movement down the shore. Individuals which recruit into the shallows appear to migrate to deeper water as they grow, the trend being more accentuated in the males. Their position on the reef may be a product of their size, sex and behavioural interactions. Sale (1969) found a progressive selection of deeper water habitats with increased body size in surgeonfish Acanthurus triostegus. Choat \& Ayling (1987) found a habitat-related pattern of size structure for fish fauna as a whole, with a general increase in fish size with depth of habitat. This trend for increasing size with depth appears to be a common feature in many fish species (Johannes 1978, Longhurst \& Pauly 1987). Since the sex of a fish is often related to size (e.g. Robertson 1972, Choat \& Robertson 1975, Jones 1984 a, c, 1987, Hoffman 1985), with males often larger than females, this size/depth trend may be indicative of a widespread tendency for differential sex distributions

The magnitude of the temporal variation in the density of Cheilodactylus spectabilis was orders of magnitude lower than spatial variation at the scales considered. Differences in abundance among habitats were consistent over a range of time scales. Similar levels of constancy in density were found on a between-year, within-year, between-day, and withinday basis. Jones (1984c) observed a similar pattern in a 5 yr study of the temperate labrid Notolabrus celidotus over 10 habitats. In some habitats significant changes in abundance were recorded, however the general pattern of distribution between habitats remained unchanged. Other studies document similar trends (e.g. Ebeling et al. 1980, Choat \& Bellwood 1985). An exception, however, were the findings of a 12 yr study of reef fish abundances made at the Poor Knights Islands (Choat et al. 1988). Those species with either small or with distant parent populations showed marked temporal fluctuations. Such large changes in density were suggested to be a function of the geographical isolation of the island and atypical of temperate reef fish populations generally.

How this lack of a regular systematic movement pattern compares to other large benthic carnivores is difficult to assess, due to the lack of detailed studies on the distribution patterns of large demersal fish. A number of studies have examined the ontogenetic movement patterns of the tropical pomadasyid HaemuIon flavolineatum (Ogden \& Ehrlich 1977, McFarland et al. 1979, Helfman et al. 1982). These studies have shown that juveniles form schools of similar sized individuals on the reef during the daylight hours, migrating at dusk into seagrass or sand areas to feed. Adults displayed a more solitary existence, although maintaining the diurnal migration pattern (Shulman \& Ogden 1987). Examples of regular feeding migrations have be found for a large number of families, including acanthurids (e.g. Fishelson et al. 1987), scarids (e.g. Ogden \& Buckman 1973), pempherids (e.g. Gladfelter 1979), and pomacentrids (e.g. Hobson \& Chess 1976). Few studies, however, have documented a lack of regular diurnal migration.

The patterns of size-structure of Cheilodactylus spectabilis with habitat type remained consistent over time. There are few differences between recent estimates of size structure and those collected 10 yr earlier in 1978. This is hardly surprising when the biology of the species is taken into account. The magnitude and frequency of changes in the structure of a population is likely to be directly related to the longevity of the species and the time frame of study. Variable recruitment is likely to have a greater effect on the population size of a short-lived species, rather than a long-lived species. C. spectabilis is an example of the latter, being both long lived and relatively slow growing (McCormick 1986) with cohorts of similar sized/aged individuals not being readily separable after the second year. Information from this study suggests the population size and age structure is the result of an accumulation of periods of generally low settlement, interspersed with years of successful, high settlement. Unfortunately, long-term studies of reef fish populations have not examined size structure and in these studies it is unknown whether temporal consistency in numbers masks an underlying instability in the age or size composition (Jones 1988).

The size-related distribution patterns of Cheilodactylus spectabilis on the reef have important ramifications to its influence as a microcarnivore on the benthic invertebrate fauna. Much work has been done on the effects of fish predation on invertebrate communities in vegetated marine habitats (review by Choat 1982). Most, however, lack information on the distribution patterns of the predators, generally assuming a uniform effect over the whole system (Virnstein 1977, Heck \& Thoman 1981, Nelson 1981, Minello \& Zimmerman 1983, Tito de Morais \& Bodiou 1984). This study showed that over $50 \%$ of $C$. spectabilis occur in the shallows, where there is a predominance of small individuals. Leum \& Choat (1980), in a study of the feeding 
of C. spectabilis, found that small-to-mid sized fish fed intensively throughout the day, while large individuals fed seldom. Furthermore, a preliminary study on the use of space within home ranges indicated that intense feeding was confined to a relatively small part of the total area regularly traversed (McCormick 1986). Consequently, if there was an effect of $C$. spectabilis feeding on the invertebrate community, it could be expected to be a localized effect, concentrated in the shallow areas of the reef. The stability of the sizestructure in an area is also of importance when considering the potential effects of fish feeding. The relative proportions and sizes of food items removed, together with the quantity per bite and the microhabitat to which feeding is directed, have all been shown to be size-related for C. spectabilis (McCormick 1986). Together, these observations indicate that without a detailed knowledge of distribution patterns, a completely false impression of the effects of feeding pressure on the distribution of prey items can be obtained.

Clearly, more population studies which incorporate elements of demography are required to enhance our understanding of the interactions of fish with their physical and biological environment. By examining the size structure and sex distribution of Cheilodactylus spectabilis over a range of time scales, this study has shown that the distribution pattern has a large element of predictability. This greatly simplifies investigation of the factors which influence this distribution pattern, and design of experiments to examine the effect of the fish on its environment.

Acknowledgements. This study is a contribution from the Leigh Marine Laboratory of the University of Auckland, New Zealand. I gratefully acknowledge the financial and logistic support of this facility. I thank Tony Ayling for access to unpublished data. I am grateful to those who discussed the work with me and commented on the manuscript: Howard Choat, Geoff Jones, Brigid Kerrigan, Mike Kingsford and Garry Russ. I also thank A. MacDiarmid, M. Meekan and B. Hickey for assisting in the field.

\section{LITERATURE CITED}

Ayling, A. M. (1981). The role of biological disturbance in temperate subtidal encrusting communities. Ecology 62: $830-847$

Choat, J. H. (1982). Fish feeding and the structure of benthic communities in temperate waters. Ann. Rev. Ecol. Syst. 13: $423-449$

Choat, J. H., Ayling, A. M. (1987). The relationship between habitat structure and fish faunas on New Zealand reefs. J. exp. mar Biol. Ecol. 110: 257-284

Choat, J. H., Ayling, A. M., Schiel, D. R. (1988). Temporal and spatial variation in an island fish fauna. J. exp. mar. Biol. Ecol. 121: 91-111

Choat, J. H., Bellwood, D. R. (1985). Interactions amongst herbivorous fishes on a coral reef: influence of spatial variation. Mar Biol. 89: 221-234

Choat, J. H., Robertson, D. R. (1975). Protogynous hermaphroditism in fishes of the family Scaridae. In: Reinboth, R. (ed.) Intersexuality in the animal kingdom. Springer-Verlag, London, p. 263-283

Cohen, J. (1977). Statistical power analysis for the behavioural sciences. Academic Press, New York

Ebeling, A. W., Larson, R. J., Alevizon, W. S., Bray, R. N. (1980). Annual variability of reef-fish assemblages in kelp forests off Santa Barbara, California. Fish. Bull. U.S. 78: 361-377

Fishelson, L., Montgomery, L. W., Myrberg, A. H. (1987). Biology of surgeonfish Acanthurus nigrofuscus with emphasis on changeover in diet and annual gonadal cycles. Mar. Ecol. Prog. Ser 39:39-47

Gladfelter, W. B. (1979). Twilight migrations and foraging activities of the copper sweeper Pempheris schomburgki (Teleosti: Pempheridae). Mar Biol. 50: 109-119

Heck, K. L., Thoman, T. A. (1981). Experiments on predatorprey interactions in vegetated aquatic habitats. J. exp mar. Biol. Ecol. 53: 125-134

Helfman, G. S. (1978). Patterns of community structure in fishes: summary and overview. Environ. Biol. Fish. 3 $129-148$

Helfman, G. S., Meyer, J. L., McFarland, W. N. (1982). The ontogeny of twilight migration patterns in grunts (Pisces Haemulidae). Anim. Behav. 30: 317-326

Hobson, E. S., Chess, J. R. (1976). Trophic interactions among fishes and zooplankters near shore at Santa Catalina Island. Fish. Bull. U.S. 74: 567-598

Hoffman, S. G. (1985). Effects of size and sex on the social organization of reef-associated hogfish, Bodanius spp Environ. Biol. Fish. 14: 185-197

Holbrook, S. J., Schmitt, R. J. (1984). Experimental analysis of patch selection by foraging black surfperch (Embiotoca jacksoni). J. exp. mar Biol. Ecol. 79: 39-64

Johannes, R. E. (1978). Reproductive strategies of coastal marine fishes in the tropics. Environ. Biol. Fish. 3: 65-84

Jones, G. P. (1984a). The influence of habitat and behavioural interactions on the local distribution of the wrasse Pseudolabrus celidotus. Environ. Biol. Fish. 10: 43-58

Jones, G. P. (1984b). Population ecology of the temperate reef fish Pseudolabrus celidotus Bloch \& Schneider (Pisces: Labridae). I. Factors influencing recruitment. J. exp. mar Biol. Ecol. 75: 257-276

Jones, G. P. (1984c). Population ecology of the temperate reef fish Pseudolabrus celidotus Bloch \& Schneider (Pisces: Labridael. II. Factors influencing adult density. J. exp. mar. Biol. Ecol. 75: 277-303

Jones, G. P. (1987). Competitive interactions among adults and juveniles in a coral reef fish. Ecology 68: 1534-1547

Jones, G. P. (1988). Ecology of rocky reef fish of northeastern New Zealand. N.Z. Jl mar Freshwat. Res. 22: 445-462

Kingett, P. D., Choat, J. H. (1981). Analysis of density and distribution patterns in Chrysophrys auratus (Pisces: Spandae) within a reef environment: an experimental approach. Mar Ecol. Prog. Ser. 5: 283-290

Legendre, L. (1987). Multidimensional contingency table analysis as a tool for biological oceanography. Biol. Oceanogr. 5: 13-28

Leum, L. L., Choat, J. H. (1980). Density and distribution patterns of the temperate marine fish Cheilodactylus spectabilis (Cheilodactylidae) in a reef environment. Mar Biol. 57: $327-337$

Longhurst, A., Pauly, D. (1987). Ecology of tropical oceans. Academic Press, Harcourt Brace Jovanovich Publishers, New York, London, Sydney 
McCormick, M. I. (1986). Spatial and temporal patterns of abundance of Cheilodactylus spectabilis (Pisces: Cheilodactylidae). M. Sc. thesis, University of Auckland

McCormick, M. I. (1989). Reproductive ecology of the large temperate reef fish Cheilodactylus spectabilis (Pisces: Cheilodactylidae). Mar Ecol. Prog. Ser. (in press)

McCormick, M. I. Choat, J. H. (1987). Estimating total abundance of a large temperate-reef fish using visual striptransects. Mar. Biol. 96: 469-478

McFarland, W N., Ogden, J. C., Lythgoe, J. N. (1979). The influence of light on the twilight migrations of grunts. Environ. Biol. Fish. 4: 9-22

Minello, T J., Zimmerman, R. J. (1983). Fish predation on juvenile brown shrimp Penaeus aztecus (Ives): the effect of simulated Spatina structure on predation rates. J. exp. mar Biol. Ecol. 72: 211-231

Nelson, W. G. (1981). Experimental studies of the decapod and fish predation on seagrass macrobenthos. Mar. Ecol. Prog. Ser. 5: 141-149

Ogden, J. C., Buckman, N. S. (1973). Movements, foraging groups, and diurnal migrations of the striped parrotfish Scarus caroicensis Bloch (Scaridae). Ecology 54: 589-596

Ogden, J. C., Ehrlich, P. R. (1977). The behavior of heterotypic resting schools of juvenile grunts (Pomadasyidae). Mar. Biol. 42: 273-280

Robertson, D. R. (1972). Social control of sex reversal in a cora] reef fish. Science 177: 1007-1009

Russ, G. (1980). Effect of predation by fishes, competition, and structural complexity of the substratum on the estabish-

This article was presented by Dr A. J. Underwood, Sydney, Australia ment of a marine epifaunal community. J. exp. mar Biol. Ecol. 42: 55-69

Russ, G. (1984a). Distribution and abundance of herbivorous grazing fishes in the central Great Barrier Reef. I. Levels of variability across the entire continental shelf. Mar Ecol. Prog. Ser 20: 23-34

Russ, G. (1984b). Distribution and abundance of herbivorous grazing fish in the central Great Barrier Reef. II. Patterns of zonation of mid-shelf and outershelf reefs. Mar. Ecol. Prog Ser. 20: 35-44

Sale, P. F. (1969). Pertinent stimuli for habitat selection by the juvenile manini, Acanthurus triostegus sandvicensis. Ecology 50 : $616-623$

SAS (1985). SAS Institute Inc. SAS/STAT Guide for personal computers, version 6 edition. SAS Institute Inc., Cary

Shulman, M. J., Ogden, J. C. (1987). What controls tropical reef fish populations: recruitment or benthic mortality? An example in the Caribbean reef fish Haemulon flavolineatum. Mar. Ecol. Prog. Ser 39: 233-242

Tito de Morais, L., Bodiou, J. L. (1984). Predation on meiofauna by juvenile fish in a western Mediterranean flat fish nursery ground. Mar. Biol. 82: 209-215

Virnstein, R. W (1977). The importance of predation by crabs and fishes on benthic infauna in Chesapeake Bay. Ecology 58: $1199-1217$

Werner, E. E., Gilliam, J. F. (1984). The ontogenetic niche and species interactions in size structures populations. Ann. Rev. Ecol. Syst. 15: 393-425

Winer, B. J. (1971). Statistical prunciples in experimental design. McGraw-Hill, London, Tokyo

Manuscript first received: May 3, 1988

Revised version accepted: February 14, 1989 